Short Communication

\title{
Preparation of $\mathrm{Sm}_{0.5} \mathrm{Sr}_{0.5} \mathrm{Co}_{0.2} \mathrm{Fe}_{0.8} \mathrm{O}_{3-\delta} / \mathrm{MWCNT}$ Composites and their electrocatalytic activities for ORR and OER
}

Yuwei Wang, Yongwang Jiang, Tao Cong, Liquan Fan", Xinyu Su, Xingmei Liu, Weichao Zhang, Xijun Liu

College of Materials Science and Engineering, Heilongjiang Provincial Key Laboratory of Polymeric Composite Materials, Qiqihar University, No.42, Wenhua Street, Qiqihar 161006, PR China

*E-mail: Liquan_Fan@163.com

Received: 9 October 2021 / Accepted: 15 November 2021 / Published: 6 December 2021

In the perovskite/carbon composite electrocatalyst, the carbon phase acts as the conductive framework to support the perovskite phase and at the same time make the current distribution more uniform and improve the electrical contact between the perovskite phase and the electrode. Here, to improve the ORR/OER activity of perovskite, $\mathrm{Sm}_{0.5} \mathrm{Sr}_{0.5} \mathrm{Co}_{0.2} \mathrm{Fe}_{0.8} \mathrm{O}_{3-\delta}$ (SSCF28) nanofibers prepared by electrospinning are mixed with multi-walled carbon nanotubes (MWCNT) to obtain SSCF28/MWCNT composite catalyst. For SSCF28/MWCNT with the optimal mass ratio, the OER Tafel slope of is 85.8 $\mathrm{mV} \mathrm{dec}^{-1}$, and the ORR Tafel slope is only $67.3 \mathrm{mV} \mathrm{dec}{ }^{-1}$. SSCF28/MWCNT (1:5) shows good bifunctional electrocatalytic performance.

Keywords: $\mathrm{Sm}_{0.5} \mathrm{Sr}_{0.5} \mathrm{Co}_{0.2} \mathrm{Fe}_{0.8} \mathrm{O}_{3-\delta}$; Multi-walled carbon nanotube; OER/ORR; Electrocatalyst

\section{FULL TEXT}

(C) 2022 The Authors. Published by ESG (www.electrochemsci.org). This article is an open access article distributed under the terms and conditions of the Creative Commons Attribution license (http://creativecommons.org/licenses/by/4.0/). 